\title{
Intra-Annular Granulation Tissue Syndrome: Clinico- Histological Study of High Intensity Zones and the Role of Percutaneous Endoscopic Lumbar Annuloplasty as Therapy with Two Years Follow-up
}

\author{
Sang-Ho Lee 1 \\ Ramakant Kumar ${ }^{2}$ \\ Jun Seok Bae \\ Luigi Andrew Sabal ${ }^{2}$ \\ Seung-Suk Park'
}

${ }^{1}$ Department of Neurosurgery, Spine Health Wooridul Hospital (SHWH), Seoul, Korea ${ }^{2}$ Orthopedic Spine Fellow, Spine Health Wooridul Hospital (SHWH), Seoul, Korea
Received November 27, 2014

Revised December 14, 2014

Accepted December 19, 2014

\footnotetext{
Correspondence

Ramakant Kumar

Orthopedic Spine Fellow, Wooridul Spine Hospital 445, Hakdong-ro, Gangnam-gu, Seoul 135-951, Korea

Tel: $+82-2-513-8947$

Fax: $+82-2-513-8154$

E-mail: giosabaldagmail.com

(C) Korean Society for Laser Medicine and Surgery

(c) This is an open access article distributed under the terms of the Creative Commons Attribution NonCommercial License (http://creativecommons.org/ licenses/by-nc/3.0) which permits unrestricted noncommercial use, distribution, and reproduction in any medium, provided the original work is properly cited.
}

\begin{abstract}
Background and Objectives
Chronic back pain has been associated with high intensity zones (HIZs) on MRI. Our objectives are to study: any correlation between HIZs on MRI and presence of granulation tissue; symptoms in patients with HIZ; therapeutic efficacy of percutaneous endoscopic lumbar annuloplasty (PELAN) in such patients.

\section{Materials and Methods}

A retrospective study was conducted in a single institution where PELAN was performed from 2009 to 2011 . All patients underwent thorough physical and radiologic evaluation. Posterior sub-annular tissue biopsy was performed intra-operatively. Clinical and functional outcome were assessed using visual analogue score (VAS), Owestry disability score (ODI), and modified Mcnab criteria. Patients were followed-up at one month, six months, one year, and two years.
\end{abstract}

\section{Results}

A total of 24 patients were included. The mean age of the study population was 47.29. Mean and minimum follow-up periods were 29 and 24 months, respectively. All patients were questioned about their symptoms. All patients complained of sitting intolerance and dramatic relief after unloading. None had neurological deficits. Mean pre-op VAS score was 7.5, significantly improving to 2.5 at 2-year follow-up, while ODI was 69.1, significantly improving to $29 ; 62.5 \%$ (15 patients) had excellent functional outcome, while good and fair outcomes were reported by $25 \%$ and $12.5 \%$ patients, respectively. Out of 24 biopsy samples, 19 patients $(79.17 \%)$ patients had positive granulation tissue findings.

\section{Conclusion}

HIZ represents granulation tissue, which may or may not be the cause of low back pain. PELAN can be a treatment modality for intra-annular granulation syndrome.

\section{Key words}

Intra-annular granulation tissue syndrome; High intensity zone; Percutaneous endoscopic lumbar annuloplasty 


\section{INTRODUCTION}

Chronic back pain is the second most common cause of consult to health care providers around the world. If left untreated, the economic, psychological and social impact on an individual and society is dismal. Multiple biomechanical etiologies for low back pain have been suggested in the literature such as: annular fissures, compressive herniated nucleus pulposus, internal disc disruption and degenerative disc disease..$^{1-5}$

Since the discovery of high intensity zone $(\mathrm{HIZ})$ on MRI by April et.al in 1992 and the subsequent evidence of neoinnervation and neovascularization in the pathogenesis of back pain, there has been new interest in the patho-mechanics and management of this entity. ${ }^{5-12}$ Multiple studies have correlated HIZ on MRI with discogram finding and concordant pain. It is also suggested that HIZs not only contains nuclear material, but also inflamed granulation tissue which is responsible for the bright signal on T2W images. ${ }^{6,10}$ However there are no studies which have correlated the HIZ finding on MRI with intra-operative biopsy of the disc material. Patients with discogenic back pain have multiple symptoms ranging from sitting intolerance to extension catch and there is a need to study these syndromic symptoms and the treatment options.

Many surgical procedures have been developed for the management of disc related pathology, from micro lumbar discectomy to percutaneous intradiscal and endoscopic treatment. ${ }^{13-16}$ Initially discectomy focused on the removal of the central part of the disc; it has had far reaching consequences in terms of reduction in disc height and propensity to develop inter-vertebral instability in long term follow-up. ${ }^{17-20}$ At present, normal and healthy disc tissue preservation is preferred when performing disc related procedures.

Since the discovery of the location of nociceptive receptors in the superficial fibers of the posterior annulus, treatment strategies have changed. ${ }^{21-23}$ There is need for location specific oriented treatment, which selectively deals with the offending pathological region without disturbing the normal disc tissue. Percutaneous endoscopic laser annuloplasty (PELAN) is an intraannular target specific procedure, which mainly eburnates the pain generating stimulus in the posterior annular region without disturbing the central nucleus. ${ }^{24}$ The objectives of this study were three fold: (a) to study any correlation between HIZs on MRI and presence of granulation tissue diagnosed microscopically from biopsied disc material. (b) To study different symptoms in patients with $\mathrm{HIZ}$ in detail. (c) To study the therapeutic efficacy of PELAN in managing such patients in terms of clinical and functional outcome.

\section{MATERIALS AND METHODS}

This was a prospective non randomized study conducted in a single institution with 24 patients who underwent the PELAN procedure from year 2009 to 2011. The inclusion criteria were as follows: (a) Patients with unremitting chronic back pain, who had received at least six months of conservative treatment; (b) Patients with an identifiable high intensity zone (HIZ) on T2w MR of the lumbar spine; (c) Diagnosis of discogenic pain confirmed by discogram; (d) Single level of disc involvement. Patients who were excluded from the study were: (a) Patients with back pain associated with radicular pain; (b) No HIZ on T2w lumbar spine MR; (c) presence of disc protrusion, extrusion and sequestration on MR; (d) More than one level of disc involvement and (e) non-discogenic etiologies such as the presence of infection and any history of neoplasm.

All patients underwent thorough evaluation including clinical history, back pain characteristics (such as duration and location) and the associated symptoms to the back pain. Other causes of back pain were ruled out through physical exam and patients with associated neurological deficit were excluded. Radiological evaluation was done with radiographs, CT scans and T1w and T2w axial, sagittal and coronal MR scans. Radiographs included: AP and lateral views as well as dynamic flexion extension views to rule out any instability.

Technical details and surgical steps have been described in great detail by the author in the author's previously published study. ${ }^{24}$ Patients underwent provocative discography preoperatively or just before the operative procedure. Provocative discography was performed with manual injection of ioxitalamate meglumine (Televrix 30 Meglymine; Guerbet, France) containing $300 \mathrm{mg} / \mathrm{mL}$ iodine concentrate, without manometry. Patients with leakage of dye through annular tear and positive provocation were included in the study. In the absence of concordant pain or unappreciated annular tear under fluoroscopy, the procedure was cancelled. The PELA procedure was done under local anesthesia with the patient in the prone position.

Intraoperative fluoroscopy (C-arm) was used to select and approach the determined level. The entry point and angle for needle placement was planned on preoperative axial MR and CT image, so as not to injure 
intra-abdominal organs (colon) or to get entangled in the spinal nerves or nerve ganglions. The entry point was made at the intersection point of 2 lines crossing the facet joint (lateral view) and horizontal to the disc space (anteroposterior [AP] view) under intraoperative fluoroscopy (Fig. 1) The skin entry point was usually 12 to $15 \mathrm{~cm}$ lateral from the midline. The surgeon then advances the needle on a trajectory that approaches the facet joint with the approximate axial needle angulation below $22^{\circ}$ so as not to touch the anterior and central nucleus. Because of the use of local anesthesia, the surgeon could communicate with the conscious patient and confirm the patient's response.

Before inserting the needle into the annulus, epidurography was used to outline neural tissues of the thecal sac and exiting nerve root so they might be avoided to prevent neural injury. Also, by using a mixture of contrast media and indigo-carmine for discography, the surgeon could confirm the annular tear site in AP and lateral view. A guide wire was then inserted through the determined trajectory and when its location was verified with fluoroscopy, a cannula followed the trajectory of the

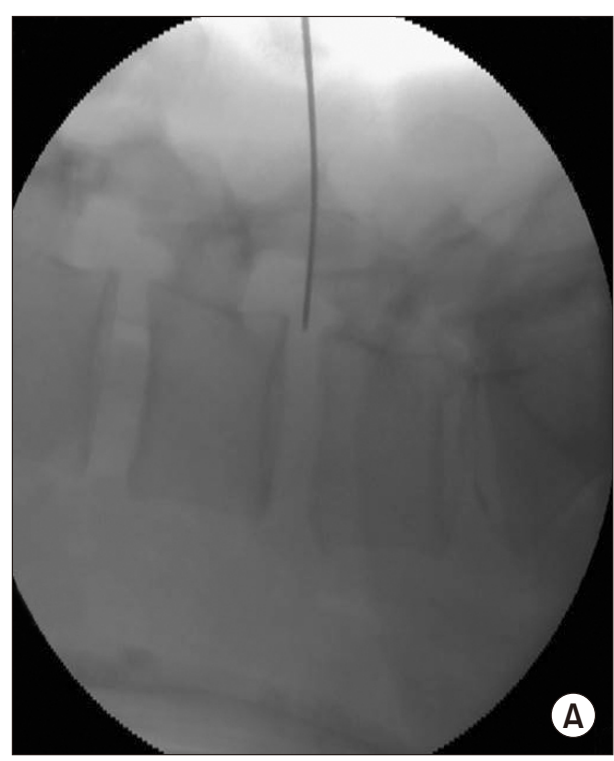

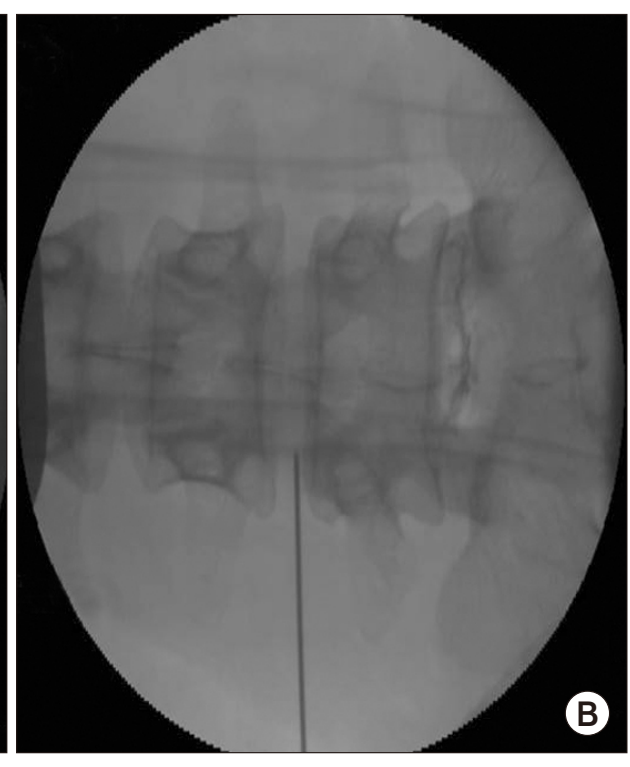

B
Fig. 1. Flouroscopic view of facet joint on lateral view (A) and disc space on AP view (B).
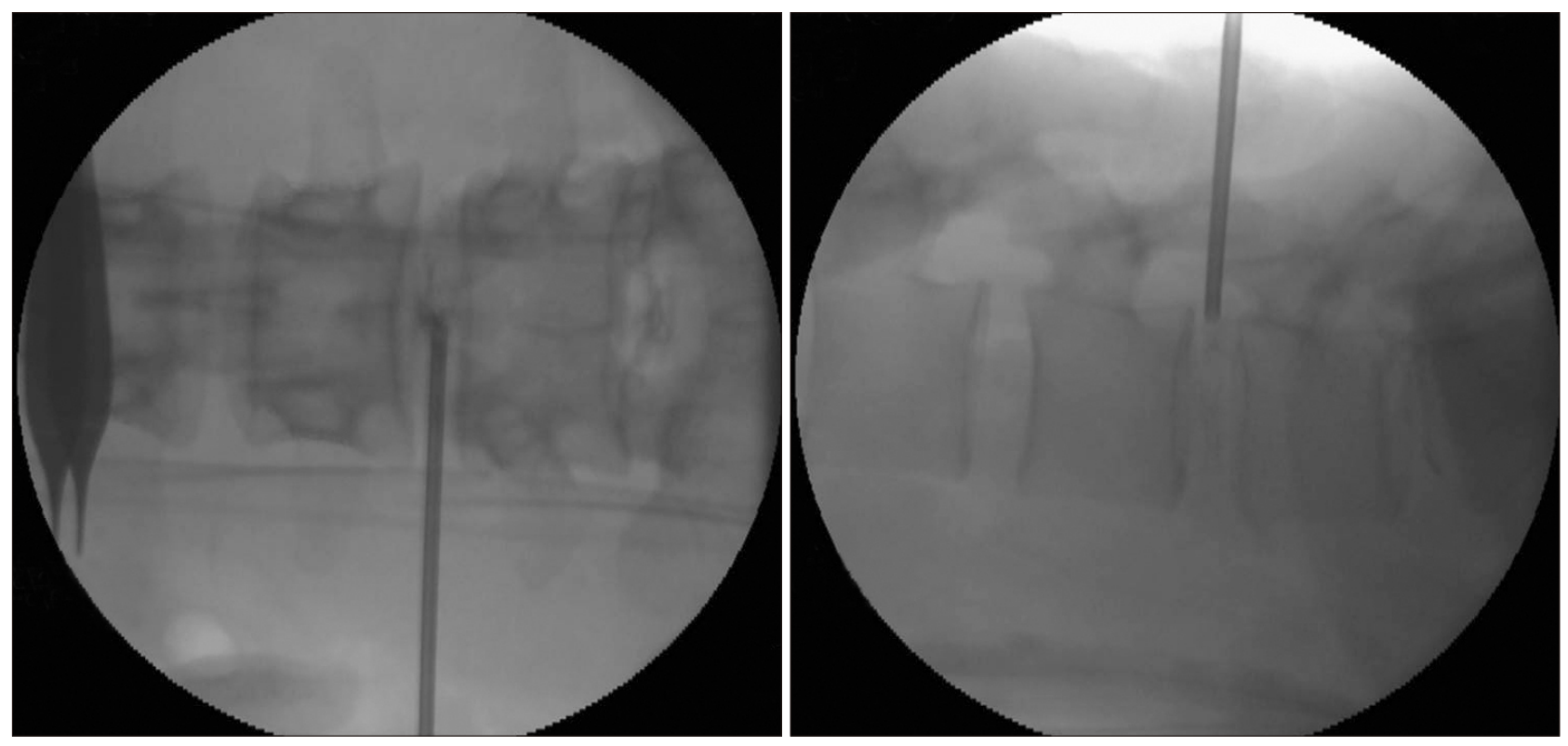

Fig. 2. Schematic representation of location of working cannula with in annulus pulposus. 


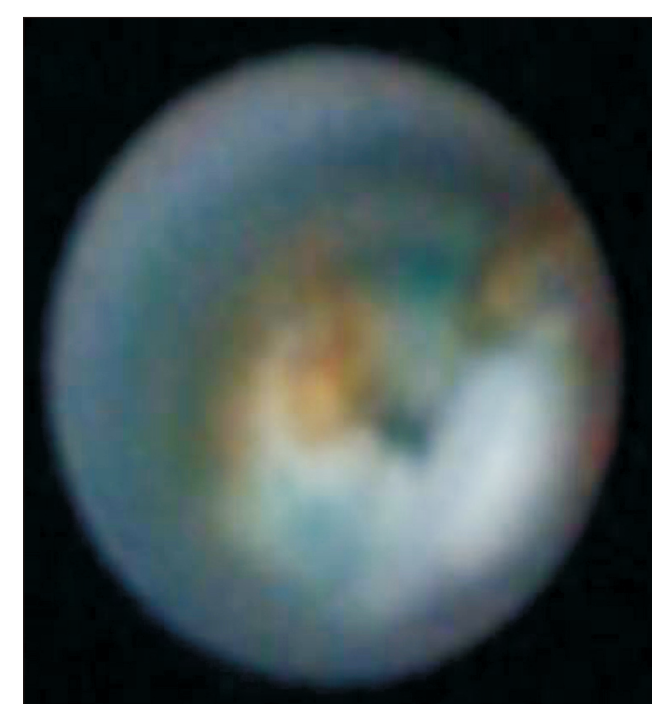

Fig. 3. Endoscopic view of inflamed nuclear material dyed blue with indigo carmine.

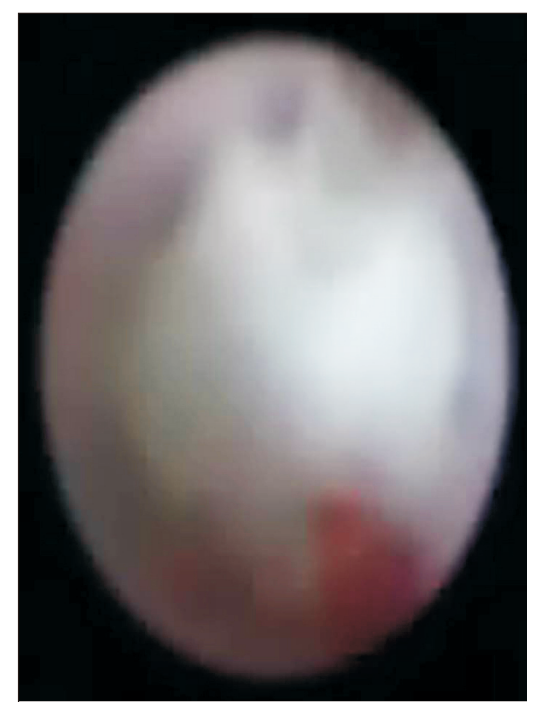

Fig. 4. Endoscopic view of damaged annular region.

guide wire. The cannula would have had penetrated the subligamentous intraannular region and not the epidural space nor the intradiscal nucleus (Fig. 2). A $3 \mathrm{~mm}$ endoscope was inserted through it. The inflamed nuclear material that had penetrated into the damaged annulus site was dyed blue by indigocarmine (Fig. 3), causing it to be readily visible under the endoscope. The damaged annulus region was blood-tinged while the normal annulus region was white, neither blood-tinged nor blue (Fig. 4).

Because the indicated patients with discogenic low back pain had granulation tissue or contained intra-

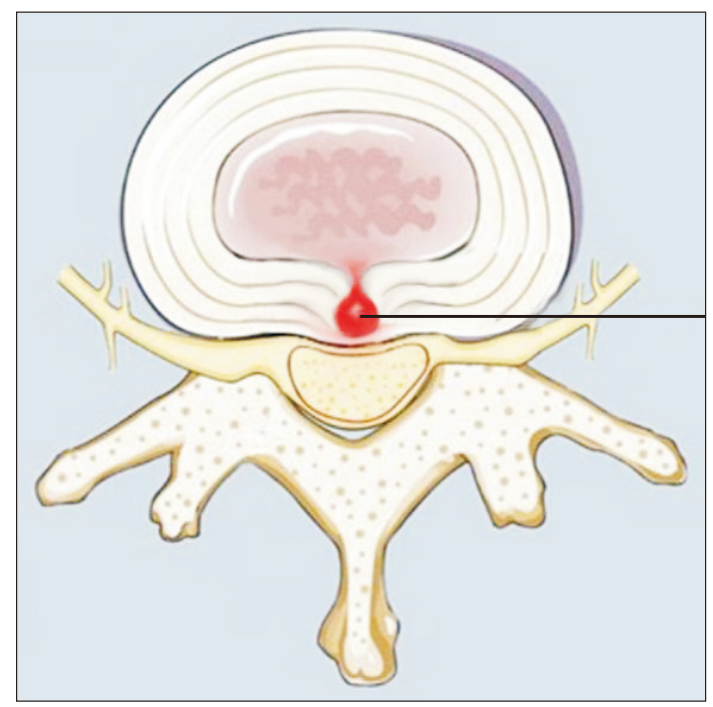

Fig. 5. Schematic illustration of PELAN.

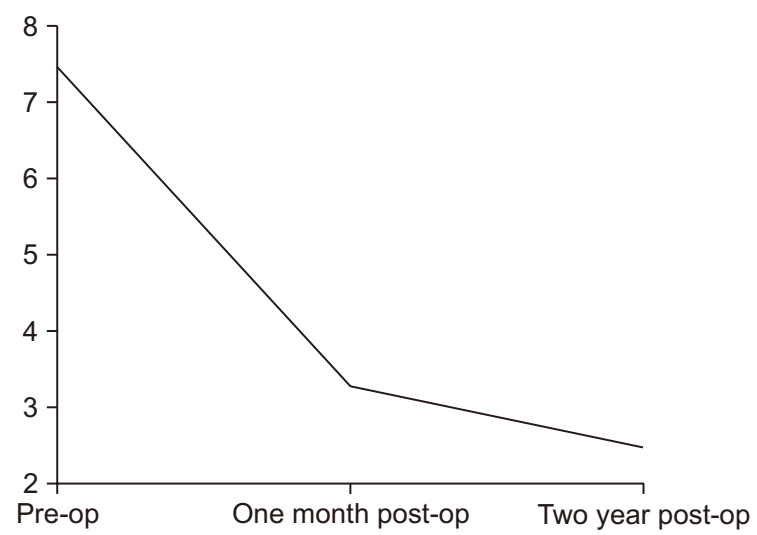

Fig. 6. VAS score in 2 years.

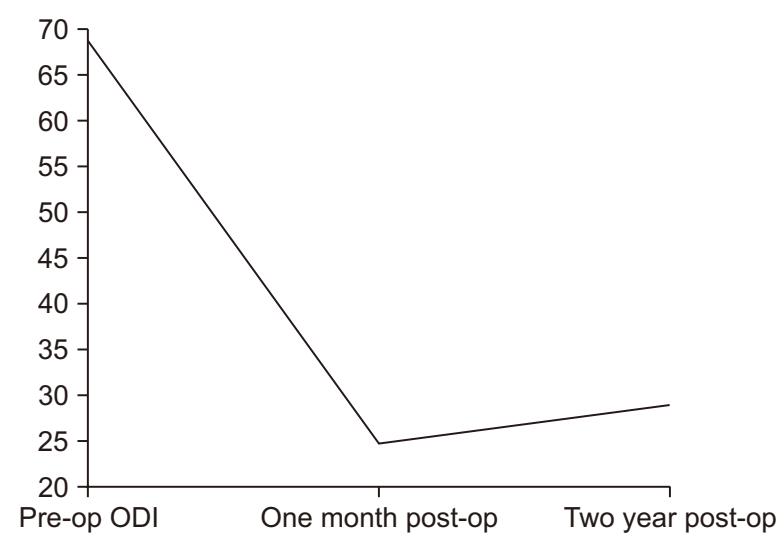

Fig. 7. ODI score in 2 years. 
discal herniations within the posterior annulus fibrosus via the posterior annular tear site, we directed the thin endoscope as closely as possible to the posterior longitudinal ligaments. Using the flexible LASE catheter of small diameter $(2.5 \mathrm{~mm})$ we could minimize the pain as well as preserve normal structure. Under the endoscopic view, the lesion was confirmed.

The Ho:YAG laser was then used to perform the thermal treatment of the damaged annulus fibrosus. The laser power level was set at 0.5 to $1.2 \mathrm{~J}(10-20 \mathrm{~Hz})$ according to the distance to the epidural space. The LASE catheter also provided continuous irrigation. At the energy levels used, the herniated granulation tissues pushed in the annular tear were ablated, whereas the damaged annulus fibrosus shrank and stiffened, nearly closing off the annular tear. In some cases when larger herniated fragments were observed during the treatment, the surgeon could use small forceps or the automated Nucleotome ${ }^{\circledR}$ (Clarus Medical, Minneapolis, MN) in the same working channel as well as the laser. After endoscopic confirmation of shrinkage of the pathologic material, the treatment was complete. The procedure usually took 30 to 45 minutes. The average total amount of laser energy delivered was 11300J.

The schematic illustration of PELA is shown in Fig. 5.

During the surgery, biopsy was taken from the posterior sub annular and intraannular region with the help of an endoscopic punch. Biopsy material was sent for histopathological examination to look for any evidence of granulation tissue.

Clinical and functional outcome were assessed using visual analogue score (VAS), Owestry disability score (ODI) and modified Mcnab criteria. After surgery all the patients were followed at one month, six months, one year and
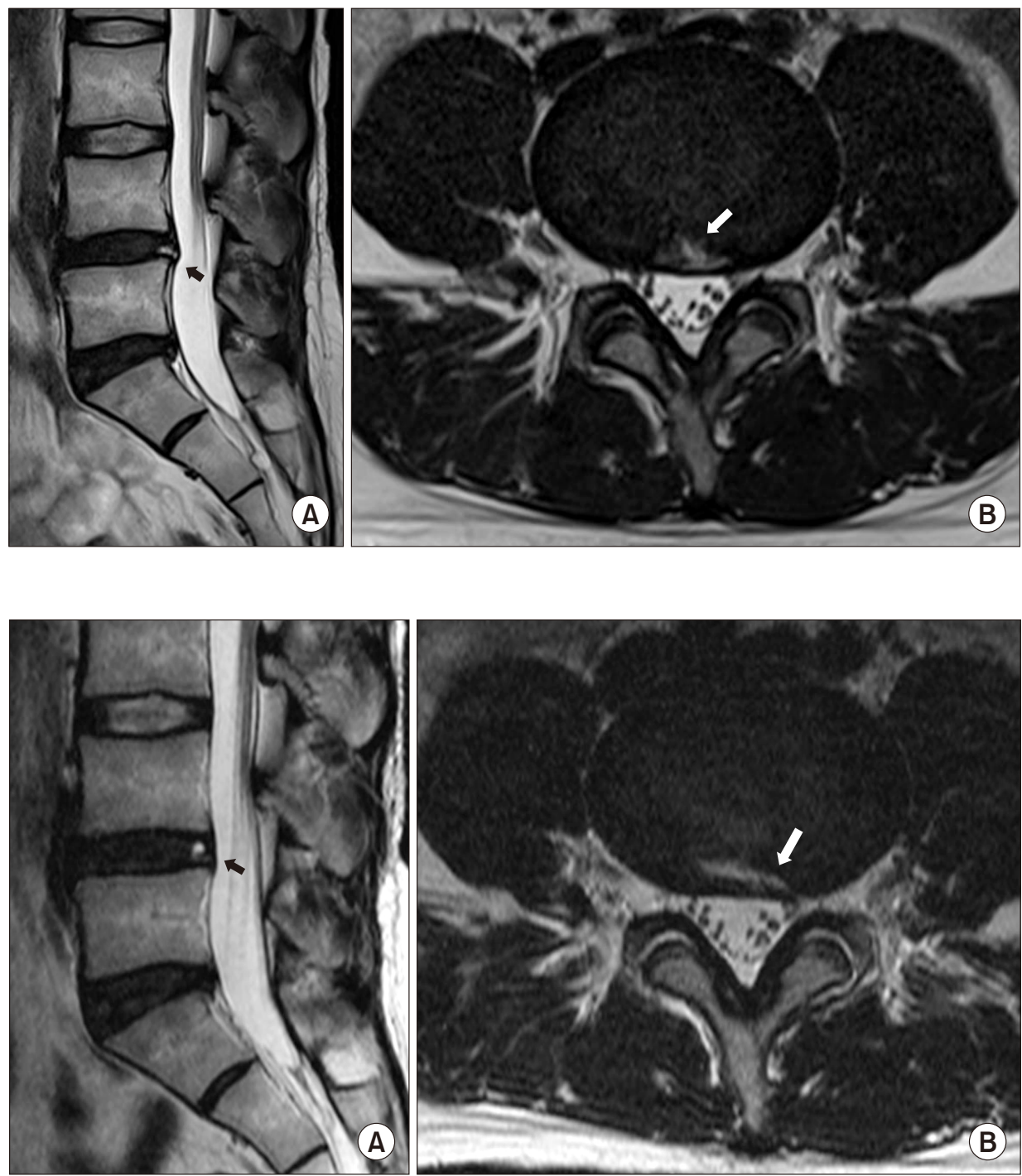

Fig. 9. Postoperative MRI showing HIZ in: (A) sagittal view (black arrow), (B) axial view (white arrow). 
two year period. All the clinical and functional indices were evaluated at each follow-up.

All statistical evaluation was performed using computer Spss 18 software. Repeated measure analysis of variance was used to compare pre-op and postop VAS and ODI scores. Paired t-test with Bonferroni method for adjustment of multiple comparisons was used to determine which period was different. Statistical significance value was set at 0.05

\section{RESULTS}

A total of 24 patients were included in the study. The mean age of the study population was 47.29 years. There were nine females and 15 male patients. Mean and minimum follow-up periods were 29 and 24 months respectively. The index level of surgery in 19 patients were L4-L5 level, while two patients each for L5-S1 and L3-L4. In a single patient, L1-L2 was the pathological disc. All patients had evidence of HIZ on MRI (Fig. 8). Post-op MRI was also done immediately after surgery and if requested by the patient on final follow-up (Fig. 9).

All patients were extensively questioned about their symptoms. The author termed the most common symptoms, the "six cardinal symptoms of intraannular granulation tissue syndrome: These cardinal symptoms and improvement in these symptoms at one month and two year follow-up have been detailed in Table 1. Sitting intolerance and dramatic relief after unloading were complained by all the patients in the study population. None of the patients had any sign suggestive of neurological deficit.

VAS score and ODI scores were assessed pre-operatively and at one month as well as 2 years follow-up. Mean preop VAS score was 7.5. There was significant improvement in VAS score at one month and two year followup ( $p=0.000$ ). It improved from mean value of 7.5 at preop to 3.3 at one month and 2.5 at two year follow-up (Fig. 6). A similar trend was noticed in the ODI score, with significant improvement from 69.1 to 29.0 at two year follow-up ( $p=0.000$ ) (Fig. 7). Modified Mcnab criteria were used to assess functional satisfaction outcome. 62.5\% (15 patients) had excellent functional outcome while good and fair outcomes were reported by $25 \%$ and $12.5 \%$ patients respectively. No patient reported poor outcome.

During annuloplasty, the disc tissue was preserved in formalin and slides were prepared and stained with haematoxylin \& eosin stain to look for granulation tissue. Out of 24 biopsy samples, 19 patients (79.17\%) patients had positive granulation tissue finding on histopathological examination.

\section{DISCUSSION}

A constant finding which has been observed in the excised painful granulation in the disc annulus is presence of neo-innervation and neo-vascularization. This is in contrast to the findings in normal intervertebral disc. ${ }^{21,25}$ It has been also reported that nerve ingrowth in the degenerated disc occurs in physical association with ingrowth of new vessel formation. ${ }^{26}$ Aprill and Bogduk et.al in their prospective study of 500 lumbar $M R I$, described a focal high intensity signal on T2w MR image and termed it high intensity zone (HIZ), they suggested that HIZ reflects annular tear and not only contains trapped intraannular nucleus but also inflamed granulation tissue, responsible for its bright signal on T2w MRI. Prevalence rate of HIZ in their series was $28.6 \%$, and most of the cases were reported at L4L5 and L5-S1 level..$^{10}$ Several other studies have found positive correlation between patients symptoms and HIZ. Saifuddin et.al in his retrospective study in a series of 58 patients, found 27 discs to be positive for HIZ and out of 27 discs, 24 discs demonstrated concordant pain response. However on discography, evidence of annular tear was found only in 18 patients. ${ }^{27}$ Similar studies by Schellhas et al., Chen et al. and Lam et al. demonstrated positive correlation with concordant pain on discography and concluded that HIZ is an indicator of painful disc and represent symptomatic torn annulus. ${ }^{728,29}$

Table 1. Symptoms associated with back pain and frequency of occurrence in our patients

\begin{tabular}{lcccc}
\hline \multicolumn{1}{c}{ Symptoms } & No. patients & Percentage of patients & Relief at 1 m & Relief at 2 yrs \\
\hline Sitting intolerance & 24 & $100 \%$ & $70 \%$ & $95 \%$ \\
Extension catch & 21 & $87.5 \%$ & $48 \%$ & $75 \%$ \\
Frequent pain attack & 23 & $95.84 \%$ & $86 \%$ & $95 \%$ \\
No intention to lifting & 20 & $83.34 \%$ & $65 \%$ & $81 \%$ \\
Difficulty to maintain single posture & 22 & $91.66 \%$ & $58 \%$ & $84 \%$ \\
Dramatic relief after unloading & 24 & $100 \%$ & $100 \%$ & $100 \%$ \\
\hline
\end{tabular}


With all the available evidence, it became an established fact that the presence of HIZ on MRI indicates a pathological lesion until Stadnik et al. reported the $56 \%$, prevalence rate of $\mathrm{HIZ}$ amongst asymptomatic volunteers. ${ }^{30}$ Similar observations contradicting the temporal association of HIZ and back pain were reported by several other authors. ${ }^{31,32}$ In 2006 a landmark study by Peng et.al tried to find out the histological nature of HIZ by selectively collecting the tissue sample from the posterior annulus during interbody fusion surgery. Out of 17 patients with $\mathrm{HIZ}$ in his series, 11 patients with concordant discogram underwent posterior interbody fusion. Histological studies revealed that, normal lamellar structures were replaced by disorganized vascularized granulation tissue and newly formed blood vessels around the tear extending from nucleus pulposus to outer region of annulus fibrosus. The author concluded that, in patients with low back pain, the HIZ seems to be a reliable marker of painful outer annular disruption. ${ }^{6}$

In this series, 24 patients with back pain having HIZ on T2w MR with positive discogram were considered for endoscopic laser annuloplasty. Before proceeding to the therapeutic procedure, we took tissue samples from the midline posterior part of the annulus under fluoroscopic and endoscopic guidance. All biopsied samples were initially preserved in formalin and then later when mounted on slices, were prepared on paraffin. Our main aim for this histological analysis was to look for any evidence of granulation tissue. Out of 24 patients, we found evidence of new blood vessel formation and free nerve endings in 19 (79.17\%) histological specimens. Five patients had no evidence of any neo vascularization. New vessel formation was mainly located in the outer superficial fibers of the annulus mixed with inflammatory cells and free nerve endings. Peng et.al in their published series did not mention what percentage of specimens were positive for granulation tissue formation, however they concluded that HIZ represents the granulation tissue in the histological specimens. ${ }^{6}$ The absence of any new blood vessels in five patients in our series might be explained by the fact that since a small diameter working channel endoscope was used in PELAN it is always not possible to visualize the tissue representing the pathological region. The location of HIZ in this series was mostly at L4-L5 region in the posterior annulus, a similar trend reported by other studies. ${ }^{7,10,27}$

Evidence from available literature support the fact that it is this granulation tissue and neuronal ingrowth in the posterior part of the annulus that is responsible for back pain in most of the cases. ${ }^{1,24,25,33,34}$ This forms the basis for percutaneous endoscopic laser annuloplasty. Lasers have been in use in medicine since 1960. Most commonly Ho-YAG laser has been used because as a pulsed laser it causes minimal damage to the adjacent normal soft tissues. Percutaneous endoscopic laser annuloplasty (PELAN) is a minimally invasive technique, which under direct visualization of endoscope, selectively eburnates the granulation tissue and nociceptive nerve endings in the annulus. Heat generation by laser also causes contraction and shrinkage of the collagen fibrils thereby sealing the defect in the annulus. PELAN uses a $2.5 \mathrm{~mm}$ endoscope through a $3 \mathrm{~mm}$ working channel contrary to a $6.5 \mathrm{~mm}$ endoscope used in percutaneous lumbar discectomy, thereby minimizing the damage to the normal soft tissues and non-pathological part of nucleus and annulus.

This technique is target oriented; accessing only the outer part of the posterior annulus whereas anterior and central part of the nucleus remain undisturbed (24). In this series all the twenty four patients had well contained disc herniations and were suffering from isolated back pain. Following treatment, there was a significant improvement in VAS score and ODI score at both one month and two year follow-up ( $p=0.000)$. Their functional outcome was assessed using Mcnab criteria; $62.5 \%$ patients had excellent outcome at two year follow-up, with none in the poor outcome category. One of our authors in his series of 30 patients was able to achieve clinical success rate of $90 \%{ }^{24}$

We also studied the symptoms of these patients in detail, assuming that patient with HIZ in their MRI might be having different set of symptoms. Apart from dull aching back pain in these patients, six different cardinal symptoms were recognized, which have been detailed in Table 1. We described it as: Intrannular granulation

tissue syndrome. Siting intolerance and dramatic relief after disc unloading was reported by all the patients in the group. After PELAN, 80-90\% had relief of their symptoms at two year follow-up. It would be difficult to say that these group of symptoms are specific to HIZ positive patients, as no studies have taken in to account the symptoms of patients with back pain in detail, a randomized study will be needed to find if at all any difference between presenting symptoms between $\mathrm{HIZ}$ positive and $\mathrm{HIZ}$ negative patients.

\section{CONCLUSION}

This study reaffirms the findings that HIZ represents granulation tissue, although it is still difficult to say that 
presence of HIZ represents symptomatic disc. However it is quite evident that, granulation tissue and free nerve ending in posterior annulus plays an important role in generating nociceptive stimulus. Excellent clinical and functional outcomes following PELAN treatment, support the above hypothesis and opens an excellent therapeutic alternative for the management of back pain. Symptoms in these groups of patients needs study in great detail with greater sample size and perhaps a randomized control study to make a distinction between HIZ positive and negative discs, if at all it exists. However we coin the term intraannular granulation tissue syndrome, as evidence suggests that granulation tissue has been implicated in most of the studies as etiology of back pain.

\section{REFERENCES}

1. Bogduk N, Windsor M, Inglis A. The innervation of the cervical intervertebral discs. Spine (Phila Pa 1976) 1988;13:2-8.

2. Bogduk N, Tynan W, Wilson AS. The nerve supply to the human lumbar intervertebral discs. J Anat 1981;132:39-56.

3. Malinsky J. The ontogenetic development of nerve terminations in the intervertebral discs of man. (Histology of intervertebral discs, 11th communication). Acta Anat (Basel) 1959;38:96-113.

4. Groen GJ, Baljet B, Drukker J. Nerves and nerve plexuses of the human vertebral column. Am J Anat 1990;188:282-96.

5. Yoshizawa H, O'Brien JP, Smith WT, Trumper M. The neuropathology of intervertebral discs removed for low-back pain. J Pathol 1980;132:95-104.

6. Peng B, Hou S, Wu W, Zhang C, Yang Y. The pathogenesis and clinical significance of a high-intensity zone (HIZ) of lumbar intervertebral disc on MR imaging in the patient with discogenic low back pain. Eur Spine J 2006;15:583-7.

7. Schellhas KP, Pollei SR, Gundry CR, Heithoff KB. Lumbar disc high-intensity zone. Correlation of magnetic resonance imaging and discography. Spine (Phila Pa 1976) 1996;21:79-86.

8. Khan I, Hargunani R, Saifuddin A. The lumbar high-intensity zone: 20 years on. Clin Radiol 2014;69:551-8.

9. Koike Y, Uzuki M, Kokubun S, Sawai T. Angiogenesis and inflammatory cell infiltration in lumbar disc herniation. Spine (Phila Pa 1976) 2003;28:1928-33.

10. Aprill C, Bogduk N. High-intensity zone: a diagnostic sign of painful lumbar disc on magnetic resonance imaging. $\mathrm{Br} \mathrm{J}$ Radiol 1992;65:361-9.

11. Karamouzian S, Eskandary H, Faramarzee M, Saba M, Safizade $H$, Ghadipasha $M$, et al. Frequency of lumbar intervertebral disc calcification and angiogenesis, and their correlation with clinical, surgical, and magnetic resonance imaging findings. Spine (Phila Pa 1976) 2010;35:881-6.

12. David G, Ciurea AV, lencean SM, Mohan A. Angiogenesis in the degeneration of the lumbar intervertebral disc. J Med Life 2010;3:154-61.

13. Freeman BJ. IDET: a critical appraisal of the evidence. Eur Spine J 2006;15 Suppl 3:S448-57.

14. Teixeira A, Sluijter ME. Intradiscal high-voltage, long-duration pulsed radiofrequency for discogenic pain: a preliminary report. Pain Med 2006; 7:424-8.

15. Appleby D, Andersson G, Totta M. Meta-analysis of the efficacy and safety of intradiscal electrothermal therapy (IDET). Pain Med 2006;7:308-16.

16. Urrútia G, Kovacs F, Nishishinya MB, Olabe J. Percutaneous thermocoagulation intradiscal techniques for discogenic low back pain. Spine (Phila Pa 1976) 2007;32:1146-54.

17. Carragee EJ, Spinnickie AO, Alamin TF, Paragioudakis S. A prospective controlled study of limited versus subtotal posterior discectomy: short-term outcomes in patients with herniated lumbar intervertebral discs and large posterior anular defect. Spine (Phila Pa 1976) 2006;31:653-7.

18. Couto JM, Castilho EA, Menezes PR. Chemonucleolysis in lumbar disc herniation: a meta-analysis. Clinics (Sao Paulo) 2007;62:175-80.

19. Goel VK, Goyal S, Clark C, Nishiyama K, Nye T. Kinematics of the whole lumbar spine. Effect of discectomy. Spine (Phila Pa 1976) 1985; 10:543-54.

20. Yorimitsu E, Chiba K, Toyama Y, Hirabayashi K. Long-term outcomes of standard discectomy for lumbar disc herniation: a follow-up study of more than 10 years. Spine (Phila Pa 1976) 2001;26:652-7.

21. Coppes MH, Marani E, Thomeer RT, Groen GJ. Innervation of "painful" lumbar discs. Spine (Phila Pa 1976) 1997;22:2342-9; discussion 2349-50.

22. Nakamura S, Takahashi K, Takahashi Y, Morinaga T, Shimada $\mathrm{Y}$, Moriya $\mathrm{H}$. Origin of nerves supplying the posterior portion of lumbar intervertebral discs in rats. Spine (Phila Pa 1976) 1996;21:917-24.

23. Nakamura SI, Takahashi K, Takahashi Y, Yamagata M, Moriya H. The afferent pathways of discogenic low-back pain. Evaluation of L2 spinal nerve infiltration. J Bone Joint Surg Br 1996;78:60612.

24. Lee SH, Kang HS. Percutaneous endoscopic laser annuloplasty for discogenic low back pain. World Neurosurg 2010;73:198206; discussion e33.

25. Freemont AJ, Peacock TE, Goupille P, Hoyland JA, O'Brien J, Jayson MI. Nerve ingrowth into diseased intervertebral disc in chronic back pain. Lancet 1997;350:178-81.

26. Peng B, Wu W, Hou S, Li P, Zhang C, Yang Y. The pathogenesis of discogenic low back pain. J Bone Joint Surg Br 2005;87:62-7.

27. Saifuddin A, Braithwaite I, White J, Taylor BA, Renton P. The value of lumbar spine magnetic resonance imaging in the demonstration of anular tears. Spine (Phila Pa 1976) 
1998;23:453-7.

28. Chen JY, Ding Y, Lv RY, Liu QY, Huang JB, Yang ZH, et al. Correlation between MR imaging and discography with provocative concordant pain in patients with low back pain. Clin J Pain 2011;27:125-30.

29. Lam KS, Carlin D, Mulholland RC. Lumbar disc high-intensity zone: the value and significance of provocative discography in the determination of the discogenic pain source. Eur Spine $J$ 2000;9:36-41.

30. Stadnik TW, Lee RR, Coen HL, Neirynck EC, Buisseret TS, Osteaux MJ. Annular tears and disk herniation: prevalence and contrast enhancement on MR images in the absence of low back pain or sciatica. Radiology 1998;206:49-55.

31. Weishaupt D, Zanetti M, Hodler J, Boos N. MR imaging of the lumbar spine: prevalence of intervertebral disk extrusion and sequestration, nerve root compression, end plate abnormalities, and osteoarthritis of the facet joints in asymptomatic volunteers. Radiology 1998;209:661-6.

32. Carragee EJ, Paragioudakis SJ, Khurana S. 2000 Volvo Award winner in clinical studies: Lumbar high-intensity zone and discography in subjects without low back problems. Spine (Phila Pa 1976) 2000;25:2987-92.

33. Natarajan RN, Ke JH, Andersson GB. A model to study the disc degeneration process. Spine (Phila Pa 1976) 1994;19:259-65.

34. Freemont AJ. The cellular pathobiology of the degenerate intervertebral disc and discogenic back pain. Rheumatology (Oxford) 2009;48:5-10. 